\title{
Revisiting the Cognitive Model of Depression: The Role of Expectations
}

\author{
Winfried Rief*a, Jutta Joormann ${ }^{\mathrm{b}}$ \\ [a] Division of Clinical Psychology and Psychotherapy, Department of Psychology, Philipps-University of Marburg, \\ Marburg, Germany. [b] Department of Psychology, Yale University, New Haven, CT, USA.
}

Clinical Psychology in Europe, 2019, Vol. 1(1), Article e32605, https://doi.org/10.32872/cpe.v1i1.32605

Received: 2018-12-21 • Accepted: 2019-02-18 • Published (VoR): 2019-03-29

Handling Editor: Cornelia Weise, Division of Clinical Psychology and Psychotherapy, Department of Psychology, Philipps-University of Marburg, Marburg, Germany

Corresponding Author: Winfried Rief, Division of Clinical Psychology and Psychotherapy, Department of Psychology, Philipps-University of Marburg, Gutenbergstraße 18, 35032 Marburg, Germany. Fax: +49 64212828904. E-mail: rief@uni-marburg.de

\begin{abstract}
Background: The cognitive model of depression was highly stimulating for a better understanding and development of treatment for depression. However, the concept of "cognition" is rather broad and unspecific, and we suggest to focus on the cognitive subset of expectation.

Method: We conducted a narrative review on the role of expectations, and present an expectationfocused model of explaining why depression tends to persist despite the occurrence of positive events.

Results: Several results from basic neuroscience to effects in clinical interventions indicate that expectations play a special role not only for the understanding of the development of mental disorders and the effects of treatment approaches, but especially for an improved understanding of the persistence of mental disorders. If expectations are a major mechanism of depression, the treatment of depression must maximize the violation of dysfunctional expectations. We also introduce the concept of immunization that describes any cognitive or behavioral strategies to reduce the effect of expectation violation experiences, and hereby contributing to expectation maintenance despite expectation contradicting events. We postulate that the development of immunization strategies could help to better understand the transition from episodic to chronic depression.

Conclusion: While in early periods of depression development, a focus on expectation change might be sufficient in treatment, the treatment of patients with chronic depression requires addressing these cognitive and behavioral immunization strategies more intensively. Further implications for treatment and research are outlined that are derived from this balance between expectation violation and cognitive immunization in depression.
\end{abstract}




\section{Keywords}

depression, persistence, expectation, expectation violation, cognitive immunization

\section{Highlights}

- A focus on "expectations" helps to better understand the maintenance of depression

- We offer a model that explains why depression persists even in the presence of positive experiences.

- Many psychological treatments focus on the violation of negative expectations, but cognitive immunization can hinder treatment success

- We suggest strategies on how to improve psychological treatments for depression by maximizing expectation violation, and minimizing cognitive immunization

\section{Expectations as Subsets of Cognitions}

The cognitive model of depression has had tremendous impact on our understanding of cognition as an underlying mechanism of psychopathology and on the development of successful treatment approaches. Cognition as a construct, however, is extremely broad, starting from perceptions, automatic thoughts, intermediate beliefs, up to schemas, selfconcepts, existential life goals and more generalized concepts (Beck \& Haigh, 2014). Moreover, the cognitive model does not differentiate among cognitions concerning the past, present, and future. In this manuscript, we will focus on the role of expectations. We will argue that expectations play a specific role in our understanding of depression and other forms of psychopathology and we will discuss advantages of an in-depth perspective of this specific construct for understanding and treating depression.

The importance of expectations as specific subsets of cognition are obvious in the definition of this construct. Expectations are estimations of the likelihood of future events, and they are triggered by internal or external events ("priors"). Expectations are by definition cognitions that deal with the future, and impact future well-being. Most people have impressive abilities to cope with momentary unpleasant feelings, pain, earache and social rejection, as long as they do not expect these aversive experiences to last forever, or to be frequently repeated in the future. Thus, expectations regarding the stability of these experiences may have considerable impact on the emotions they elicit. Considering that psychological interventions are not able to change the past, and that addressing issues of the present is only of relevance if it impacts on the future, one major goal of psychological interventions should focus on improving the quality of life in the future of patients. Expectations offer the link between present state and future well-being. 
Other observations support the special role of expectations. Placebo- and nocebo-research has shown that a patient's expectations determine the success of various medical interventions, ranging from antidepressant pills to heart surgery (Enck, Bingel, Schedlowski, \& Rief, 2013; Rief, Bingel, Schedlowski, \& Enck, 2011). Therefore, expectations can be considered the most frequently investigated mechanism of treatment success in health care systems because this mechanism has been shown to play a role in nearly all fields of medicine (Schedlowski, Enck, Rief, \& Bingel, 2015). A meta-analysis of the association between treatment expectations and treatment outcome for psychological treatments confirmed the special role of patients' treatment outcome expectations (Constantino, Arnkoff, Glass, Ametrano, \& Smith, 2011), a result that was also found for psychological treatments of mental disorders or chronic pain (Cormier, Lavigne, Choiniere, \& Rainville, 2016; Delgadillo, Moreea, \& Lutz, 2016). Expectations predict the transition from acute pain to chronic pain, and the persistence of pain symptoms (Gehrt et al., 2015; Holm, Carroll, Cassidy, Skillgate, \& Ahlbom, 2008).

Modern neuroscience further supports the importance of focusing on predictions/ expectations. Whereas former models of the brain mainly considered its function as passively waiting for sensory input before processing it, modern models consider the brain a "prediction coding machine", continuously creating predictions about what will happen next (Seth, Suzuki, \& Critchley, 2012). "Prediction errors" trigger selective attention, and they are able to stimulate learning processes. Thus, the brain`s predictions steer perception, attention, and information processing in general. The parallel between the neuroscientific concepts of prediction and prediction error versus the more applied concepts of expectation and expectation violation is obvious (D’Astolfo \& Rief, 2017). Of further relevance is the blunted reward processing in depression (Pizzagalli, 2014; Wilson et al., 2018), which could help to understand why depressed patients do not update negative expectations. The "Bayesian brain" offers a computational perspective on mood as creating and updating "priors" over uncertainty (Clark, Watson, \& Friston, 2018). Finally, expectations also offer a link between mind and body: they trigger anticipatory physiological reactions. The anticipation of threat triggers physiological fight-flight-reactions. The anticipation of pain activates the somatosensory fields that are responsible for pain perception (Koyama, McHaffie, Laurienti, \& Coghill, 2005), but also brain functions that are responsible for pain control (Wager, Scott, \& Zubieta, 2007).

Whereas expectations as mechanisms of treatment success are frequently investigated, the specific role of expectations as a mechanism of disorders and in the maintenance of mental problems is a less frequently studied topic. However, expectations can play a special role in improving our understanding of transdiagnostic processes, hereby offering a link to the RDoC-approach (Insel, 2014). Anxiety disorders and phobias are by definition expectation disorders, and also for associated fields such as OCD-associated disorders, expectations can be considered a core feature contributing to the persistence of 
clinical problems (Rief \& Glombiewski, 2017). However, the role of expectations in depression is less obvious, and this will be discussed in the next section.

\section{The Cognitive Model and the Specific Role of Expectations in Depression}

The cognitive model of mental disorders goes back to formulations of ancient Greek philosophers, such as Epiktet (born about 50 A.D.). It postulates that negative affective states develop not because of direct external influences (e.g., social rejection), but because of the interpretation of these external and internal events. It was the merit of A.T. Beck to translate this approach to improve our understanding of depression. Beck's original formulation of the cognitive triad in depression can be easily transformed to expectations: negative expectations for outcomes relevant to the self, negative expectations about other's behavior, and finally negative expectations about future events. The cognitive model was supported by various experimental studies, summarized elsewhere (Gotlib \& Joormann, 2010; Joormann \& Quinn, 2014).

The standard assessment of dysfunctional attitudes (Dysfunctional Attitudes Scale DAS; Oliver \& Baumgart, 1985) targets various expectations, but also covers other cognitions considered to be specific to depression. However, the question arises whether other cognitions have explanatory value for depression beyond the value of depression-specific expectations. To investigate this question, we developed a self-rating scale to assess depression-specific expectations. Using a path analytical approach, we analyzed whether other cognitive aspects of depression explain additional variance, if the role of depression-specific expectations was controlled (Kube et al., 2018c). In this study, depressionspecific expectations had a clear association with depression, while other cognitions did not significantly add to this association. This confirms the special illness-relevant role of expectations as an important subgroup of cognitions.

Kube and colleagues (Kube, D’Astolfo, Glombiewski, Doering, \& Rief, 2017) developed a depressive expectations scale that allows to assess situation-specific expectations in major depression.

This scale includes 25 items. The depression-specific expectations can be clustered into four subgroups: Expectation of social rejection, expectation of (lack of) social support, expectation of ability to regulate mood, and expectations about the ability to perform cognitive tasks and about the likelihood of professional achievements. The advantage of this scale is that all its specific items can be directly translated into behavioral experiments, which offer the opportunity to assess expectations in depressed patients, to motivate them to test them, and to modify expectations after expectation violation experiences. Thus treatment of depression can be reformulated as an intervention to change dysfunctional expectations, mainly via the exposure to expectation violating situations (see Figure 1). 
While typical CBT approaches also cover some of these strategies, our plea is to better focus on expectation change not only in anxiety treatment (Craske, Treanor, Conway, Zbozinek, \& Vervliet, 2014), but also in depression treatments. One future gain of focusing on expectation could be the development of more effective and economic interventions for depression.

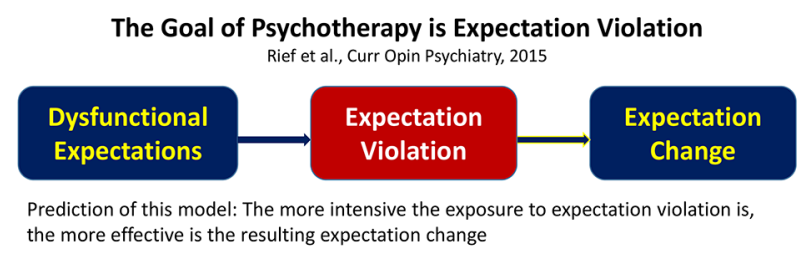

Figure 1. Psychological treatment as expectation violation.

Depression has been also linked to reward expectancy (Greenberg et al., 2015). Not expecting reward and not expecting positive events is closely associated with depressive states. Moreover, it has been postulated that depression is mainly characterized by a lack of positive expectations (instead of increased negative expectations); a concept that was also confirmed using longitudinal designs (Horwitz, Berona, Czyz, Yeguez, \& King, 2017).

\section{The Role of Cognitive Immunization in Depression}

If negative expectations are a core part of depression, the crucial question is why these negative expectations persist, even after new positive experiences ("expectation violating situations"). Whereas difficult life conditions or critical life events can lead to the development of negative expectations, and thereby contribute to the development of episodes of depression (Heim, Newport, Mletzko, Miller, \& Nemeroff, 2008; McLaughlin et al., 2017; Nelson, Klumparendt, Doebler, \& Ehring, 2017), the process of persistence of these negative expectations is still poorly understood. Even patients with depression experience positive life events, positive interactions, successful performances, but most of these events do not lead to a change in negative expectations, and development of positive expectations. Therefore, we introduced another construct in our depression model that helps to understand the persistence of negative expectations even if positive experiences occur. This concept is "(cognitive) immunization". It describes all cognitive (and sometimes also behavioral) processes to invalidate the effect of positive, expectation violating experiences. While we will focus on cognitive immunization processes, behavioral strategies can also contribute to immunization: avoiding expectation-violating situations, selective attention and ignoring stimuli that transport the contradicting information are just a few examples. 
These processes can also be observed in psychological interventions. It happens when psychotherapists try to induce positive, disconfirming experiences, but patients continuously invalidate them. Typical invalidation strategies are declaring these experiences as exceptions to the rule ("if someone is friendly with me, this is only the exception to the rule that people dislike me"; "you, as a psychotherapist, are only friendly with me because you are getting paid for it"), or invalidation of a positive situation in general ("although I succeeded in this exam, in other, much more important exams, I will fail").

Many psychological interventions aim to violate negative expectations of patients. They can be even optimized in optimizing expectation violation experiences. However, as shown in Figure 2, cognitive immunization can contribute to the invalidation of expectation violation effects. Thus treatment aims should be reformulated to maximize expectation violation effects, and to minimize (cognitive) immunization processes.

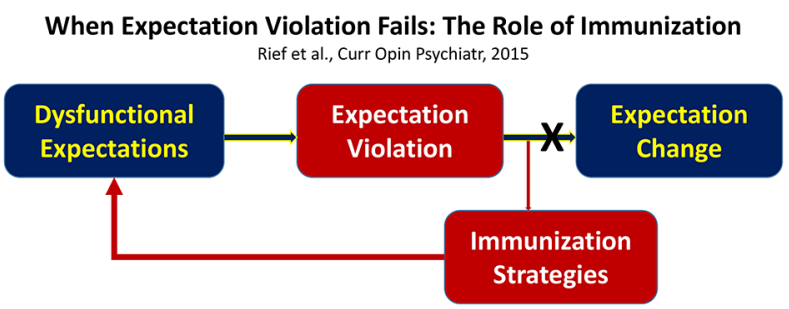

Figure 2. Expectation violation and cognitive immunization.

\section{A Stochastic Understanding of Expectation Change}

The neuroscientific prediction error paradigms have been extended by stochastic approaches, and this extension is also helpful to better understand expectation maintenance versus expectation change in depressed patients. If healthy people develop the expectation that most people are quite friendly, they interpret a broad variety of the behavior of the person with whom they're interacting as confirmation of their expectations (see Figure 3, top). Even neutral events (see arrow) confirm the positive expectations about the behavior and intentions of others. This is a potential explanation for the reported optimism bias of healthy people to memorize neutral events as being positive, and to expect positive outcomes even without any information supporting this expectation (Sharot, Riccardi, Raio, \& Phelps, 2007). Expectations form an interpretation bias towards their confirmation, and this sticking to expectations can be postulated to have an evolutionary meaning, providing stability in humans' life. Moreover, expectation confirmation can be postulated to be a typical automatic process, not requiring much cognitive resources, while the revision of expectations can be more demanding. To really challenge long-held expectations, other highly discrepant and powerful experiences are necessary. In healthy 
people, this means that only very harsh social rejection or traumatizing events really challenge their positive expectations about future events.

\section{Prediction error model (healthy controls): "most people are quite friendly"}

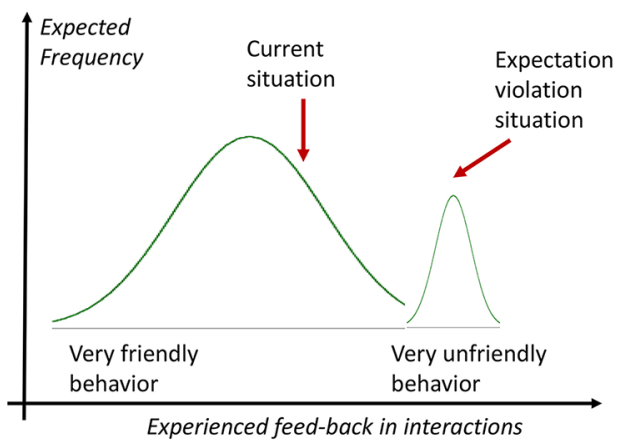

\section{Prediction error model (depressed patients): „most people are quite unfriendly"}

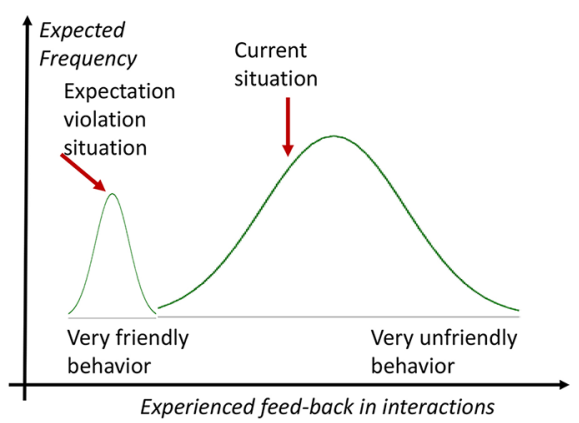

Figure 3. A stochastic model of expectation maintenance.

When developing depression, the curve of expectations appears to move to the more negative part (see Figure 3, bottom). Most events are interpreted as confirmation of a negative view of the world. Even neutral experiences may be considered as confirmation of negative expectations (see arrow). In other words: The very same experience that confirms positive expectations in healthy persons can confirm negative expectations in depressed patients. Again, to change negative expectations of depressed patients, very powerful, clearly distinguishable positive experiences are necessary. This example highlights why normal experiences and their attribution (e.g. in cognitive work) sometimes do not lead to any changes of negative expectations; effortful cognitive evaluations do not auto- 
matically lead to changing automatic processes of confirmations of negative expectations.

\section{Experimental Studies Investigating Expectation and Cognitive Immunization in Depression}

Kube et al. (Kube, Rief, Gollwitzer, \& Glombiewski, 2018b) investigated the interplay of expectation manifestation and expectation change in depression quite elegantly using an experimental paradigm. Participants received a negative performance expectation ("the following test on emotional intelligence is hard to succeed”). Afterwards, participants received different tasks on emotional intelligence that are difficult to evaluate which answers are correct. During the first trials, participants received the feedback that they were not successful, as expected. Both healthy controls and depressed patients developed similar negative expectations after these experiences (Kube, Rief, Gollwitzer, Gärtner, \& Glombiewski, 2018a). However, after several failures, performance feedback switched to more frequent positive results ("expectation violation"). In accordance with the depression model mentioned above, healthy controls changed their negative expectation to positive, while negative expectations of depressed patients persisted despite positive feedback.

In a second experiment, the same authors introduced either instructions that supported cognitive immunization strategies ("the following test is not really valid, but just a weak indicator of performance"), while others received strategies aimed to inhibit cognitive immunization ("this is a really powerful and valid test"). If depressed patients received strategies that inhibited cognitive immunization, the change to positive feedback resulted also in a change of negative expectations to positive expectations (Kube et al., 2018a). In other words: if cognitive immunizations are blocked in depressed patients, patients can benefit from positive experiences. This offers new foci for treatment planning and prevention of treatment failures in depression.

These effects are in line with other studies investigating cognitive adaptation processes in depression. Depressed persons have less favorable success expectations, and show a tendency to self-confirmation of negative attitudes (Morris, 1997). Further evidence comes from a study of Everaert and others (Everaert, Bronstein, Cannon, \& Joormann, 2018) who found that depressed patients do not only have a negative interpretation bias, but also showed a reduced revision of negative interpretations by disconfirmatory positive information. Liknaitzky and colleagues confirmed that patients with depression have a reduced ability to update interpretations after receiving expectation violating information (Liknaitzky, Smillie, \& Allen, 2017). Of note, this effect was independent of the direction of expectation violations. 


\section{Treatment Implications of the Expectation Model of Depression}

The implications for psychological treatments can be reduced to two main strategies: amplifying the effect of expectation violations if positive experiences occur, and reducing the effect of cognitive immunization. First experiences with these foci in the work with patients were quite encouraging: patients can easily adapt this expectation model, and understand what is meant by cognitive immunization. After such a psychoeducational period, both typical expectations associated with the depressive disorder, but also cognitive immunization strategies that occur in everyday experiences when positive events occur, can be collected. Instead of continuing with cognitive dispute techniques like in cognitive therapy, patients are informed that humans often maintain negative expectations even if positive experiences occur. Therefore, they are encouraged to develop more openness for experiences that are not in accordance with current expectations. Considering the reduced motivation for complex and effortful cognitive processes in many patients with depression, we are working on developing more and more attention-based strategies that do not require complex cognitive reasoning.

Patients must be sensitized for the perception of relevant information, before starting with behavioral experiments. What would be the first stimuli indicating that expectations could be wrong? What kind of immunization strategies can be expected by this patient, if expectation violation occurs? What could be possible strategies to avoid the negative effect of cognitive immunization? Only after such a cognitive preparation period, are behavioral experiments testing negative expectations executed.

This strategy can easily be extended with a behavioral component. What kind of patient's behavior would maximize the likelihood of confirmations of negative expectations (e.g., avoiding eye contact although you hope for positive interaction with others; not preparing for an exam because expecting to fail anyway; ...). After collecting behavioral patterns that serve to confirm negative expectations, the question can be reversed: What would be behavior patterns that minimize the likelihood of fulfillment of negative expectations? Not surprisingly, these kinds of behaviors should be shown during subsequent behavioral experiments. Table 1 shows a structure of such an expectation focused psychological intervention; further details can be found elsewhere (Rief \& Glombiewski, 2016, 2017).

This brief guideline shows that expectation-focused psychotherapy is not a completely new approach, but more like an improved focus on most relevant cognitive and behavioral aspects in depression. While full evaluation trials in depression are lacking, we have positive evidence for expectation-focused approaches from other clinical fields. Exposure therapy in anxiety disorders has been reformulated as a therapy to disconfirm negative expectations, and to increase inhibition of avoidance behavior (Craske, 2015; Craske et al., 2014). In pain disorder, many patients report "fear avoidance" behavior which can be considered as a special expectation pattern of chronic pain. If these patients were treated 
Table 1

The Steps of Expectation-Focused Psychological Interventions

Why are expectations maintained despite contradicting information? Examples of queries and patients' reflections as part of the psychoeducation

What are my specific expectations?

Others don't like me.

How can I check whether my expectations are valid?

Go to a party and check whether people talk to me.

What are signals, perceptions, observations, that would show me that my expectations are disconfirmed?

Others talk to me; others initiate eye contact

What kind of immunization strategies do I typically use in such a situation?

Thought: "They only look at me because they have negative thoughts about me"; I look away; If somebody talks to me, this is just on account of being polite $-\mathrm{s} /$ he has no special interest in me.

How can I deal with my immunization strategies?

Accept negative thoughts, but be open for contradicting experiences; don't look away

Results of behavioral test

People came and talked to me

What are further situations to test my expectations?

At work during coffee breaks

How should I behave to make my negative expectations come true?

Avoid eye contact; stand away from others, facial expression of bad mood

How should I behave to make my negative expectations not come true?

Stand closer [...]; search eye contact; don't walk away [...]

Results of reality checks

I was concerned that others don't like me. However, I made it quite difficult for them to show me some sympathy. And I use a lot of "immunization strategies" if positive events occur.

with a highly focused expectation-based exposure intervention, they showed the most impressive improvements even in treatment arms with less treatment sessions than comparative treatments (Glombiewski et al., 2018). Obviously, the improved focusing in pain patients led to more effective, but also more economic interventions.

An expectation-focused approach was also used for a better preparation of patients undergoing heart surgery. Pre-operatively, patients received an optimization of expectations about how life can continue after successful heart surgery. Such an expectation-focused intervention was compared to an emotionally-supportive intervention, and to standard medical care. Although the expectation-focused intervention was just two sessions in person, two phone calls (before surgery) and one booster phone call after sur- 
gery, patients in this arm showed the lowest disability scores six month after surgery (Rief et al., 2017). It is most impressive that such a low dose intervention achieved these striking effects. With more than 120 patients in this trial, it can be postulated that many risk factors and life problems were prevalent in these patients that were not addressed at all during the psychological interventions (e.g., marital conflicts, adverse early life experiences); however, quality of life improved substantially just by improving expectations. This is a further argument to better focus on crucial mechanisms that maintain mental, behavioral and even physical disorders (Holmes et al., 2018). Current depression treatments should be optimized to change dysfunctional expectations according to the principles outline above, and these treatments should be subject to further evaluation.

\section{Implications for Research}

Several hypotheses can be derived from the expectation model of depression that should be a further subject of investigation. First, it is postulated that healthy individuals show more immunization strategies to prevent them from the effects of negative experiences than depressed patients. If healthy individuals are repeatedly exposed to positive events, and subsequently negative experiences occur, we expect them to stick to positive expectations, and to activate immunization strategies. This is in line with some studies indicating that depressed patients are sometimes more "realistic" than healthy individuals, because healthy individuals show an optimism bias (Sharot, Korn, \& Dolan, 2011). This can be also considered as a resilience mechanism of healthy people (Brown, 2012).

With the first depressive episodes, the expectation curve is hypothesized to move to a more negative level. This change could be induced by negative experiences that trigger the first depressive episode, but also the depressive episode itself is associated with a change of expectations. If the expectation curve has been moved to the more negative side, this could receive a self-maintaining functionality and is resistant to change. After this move has happened, depressed patients could tend to interpret neutral events as confirmation of their negative expectations, while healthy controls interpret the same neutral experiences as confirmation of their positive view of the world. Again this dynamic can be subject to experimental, cross-sectional and longitudinal studies, to better understand and confirm ongoing mechanisms.

Another hypothesis is that only very salient positive information is able to modify negative expectations in depressed patients. This could be studied with experimental designs to investigate the effects of expectation development, expectation persistence and change to the positive or to the negative direction.

The above described expectation model may also be a model to better understand the process of persistence of depressive episodes. We hypothesize that patients with persistent depression show more immunization strategies than patients with episodic depression, in particular to invalidate the effects of positive experiences. This sticking to nega- 
tive expectations is further supported by automatic information processes, while expectation change is frequently associated with effortful cognitive processes. Again, this has implications for treatment planning. The more chronic the depressive state is, the more relevant it might be to address cognitive immunization strategies in patients.

To summarize, several hypotheses of the expectation model of depression can be extracted that can be subject to further evaluation. It not only invites observational studies, but also more mechanistic research using experimental designs. Further paradigms should be developed to establish and modify expectation processes that should have special ecological validity for affective disorders.

\section{Linking the Expectation Model of Depression With Other Psychological Concepts}

The suggested expectation model of depression focuses on aspects of how negative expectations develop, how they contribute to depression-specific symptoms and disability, and why negative expectations are maintained even if contradicting positive events occur. Such a focus offers various links to other prominent depression concepts, and a few of them will be addressed.

Neuroscience has shown that the expectation of negative emotions (e.g. pain) activates brain areas that are responsible for this emotion, and hereby facilitates the expected perception of the corresponding negative experience (Atlas \& Wager, 2012; Keltner et al., 2006; Koyama et al., 2005; Wager et al., 2004). This implies that the manifestation of expectations supports the persistence of negative mood that is associated with the expected negative experience. For the development of expectations, associative learning processes (Rheker, Winkler, Doering, \& Rief, 2017), observational learning (Vögtle, Barke, \& KönerHerwig, 2013) or instructional learning can contribute.

To overcome negative expectations, powerful expectation-violating positive experiences are necessary. However, this requires an individual to attend to this new information, to react to its positive content, and to modify and memorize the revised version of expectations. For this process, reward sensitivity, a concept that is closely linked to neurophysiological processes in depression, can be crucial (Alloy, Olino, Freed, \& Nusslock, 2016). Blunted reward sensitivity was also found in relatives of depressed patients (Liu et al., 2016). The postulated role of reward insensitivity is in line with recent findings that patients with depression show reduced revision of negative interpretations by disconfirmatory positive information (Everaert, Bronstein, Cannon, \& Joormann, 2018).

A revision of negative expectations requires a detailed perception and memorization of expectation-violating experiences. However, many patients with depression suffer from unspecific autobiographical memory reports (Kim, Yoon, \& Joormann, 2018; Sumner, Griffith, \& Mineka, 2010). According to the ViolEx-model of revising expectations (Rief et al., 2015), a revision of expectations requires a very specific definition of 
specific expectations a priori, and a clear comparison of expected versus experienced specific outcomes. If experiences are memorized only vaguely, their potential power to stimulate expectation violations is only low. This notion is in accordance with the fact that abstract ruminations lead to more regrets about past decisions than concrete ruminations (Dey, Joormann, Moulds, \& Newell, 2018).

Repetitive negative thinking, ruminations and worrying are also major features of depression (Gotlib \& Joormann, 2010; McEvoy et al., 2018). These strategies can be considered as preventing the change of negative expectations, even when positive events occur. Therefore, a close link between these cognitive processes and immunization strategies exists.

Persistent depressive disorder is frequently associated with negative early life experiences and the development of insecure attachment styles. While negative life events can trigger the establishment of various negative expectations directly, insecure attachment styles can be also reformulated as negative relationship expectations. An association between attachment and depression was frequently shown; this association is mediated via social anxieties (Manes et al., 2016). Social anxieties (like all anxiety disorders) can be mainly understood as expectation disorders. Several psychological interventions try to address these relationship expectations, and the active formulation of a "transference hypothesis" in CBASP is a typical example (McCullough, 2000; McCullough et al., 2011). Obviously, many psychological interventions include explicit or implicit interventions attempting to change relationship expectations, although an even more focused and explicit work with relationship expectations seems promising.

With this subchapter, we wanted to highlight that the expectation model of depression is able to integrate other evidence-based approaches of depression research, and it invites to link this concept with others. While these are just a few examples, further conceptual work is possible and needed.

\section{Closing Remarks}

While the cognitive model of depression was highly stimulating for a better understanding, improved conceptualization and development of treatment for depression, we suggest that it is time to better specify this approach. Several results from basic neuroscience regarding effects in clinical interventions indicate that expectations can play a special role not only for the understanding of the development of mental disorders and effects of treatment approaches, but especially for an improved understanding of persistence of mental disorders. Therefore, we also introduced the concept of immunization to describe any cognitive or behavioral strategies to reduce the effect of expectation violation experiences, and hereby contributing to expectation maintenance despite expectation contradicting events. We postulate that the development of immunization strategies could, in particular, be of relevance for the transition from episodic to chronic depression. While in 
early periods of depression development, a focus on expectation change might be sufficient in treatment approaches as long as it respects some of the principles mentioned above, the treatment of patients with persistent depressive disorder requires more and more to address these cognitive and behavioral immunization strategies.

We understand our manuscript mainly as stimulating further research and using this conceptual framework, instead of presenting a final model. First experimental results confirm its usability, and first clinical experiences encourage this approach as something that is easily explained to patients who found it very helpful. However, the model of the interplay between expectation processes and immunization strategies should be subject to further evaluation.

Funding: The authors have no funding to report.

Competing Interests: Winfried Rief is Editor-in-Chief of Clinical Psychology in Europe but played no editorial role for this particular article.

Acknowledgments: The authors have no support to report.

\section{References}

Alloy, L. B., Olino, T., Freed, R. D., \& Nusslock, R. (2016). Role of reward sensitivity and processing in major depressive and bipolar spectrum disorders. Behavior Therapy, 47(5), 600-621. https://doi.org/10.1016/j.beth.2016.02.014

Atlas, L. Y., \& Wager, T. D. (2012). How expectations shape pain. Neuroscience Letters, 520(2), 140-148. https://doi.org/10.1016/j.neulet.2012.03.039

Beck, A. T., \& Haigh, E. A. P. (2014). Advances in cognitive theory and therapy: The generic cognitive model. Annual Review of Clinical Psychology, 10(1), 1-24. https://doi.org/10.1146/annurev-clinpsy-032813-153734

Brown, J. D. (2012). Understanding the better than average effect: Motives (still) matter. Personality and Social Psychology Bulletin, 38(2), 209-219. https://doi.org/10.1177/0146167211432763

Clark, J. E., Watson, S., \& Friston, K. J. (2018). What is mood? A computational perspective. Psychological Medicine, 48(14), 2277-2284. https://doi.org/10.1017/S0033291718000430

Constantino, M. J., Arnkoff, D. B., Glass, C. R., Ametrano, R. M., \& Smith, J. Z. (2011). Expectations. Journal of Clinical Psychology, 67(2), 184-192. https://doi.org/10.1002/jclp.20754

Cormier, S., Lavigne, G. L., Choiniere, M., \& Rainville, P. (2016). Expectations predict chronic pain treatment outcomes. Pain, 157(2), 329-338. https://doi.org/10.1097/j.pain.0000000000000379

Craske, M. G. (2015). Optimizing exposure therapy for anxiety disorders: An inhibitory learning and inhibitory regulation approach. Verhaltenstherapie, 25(2), 134-143.

https://doi.org/10.1159/000381574 
Craske, M. G., Treanor, M., Conway, C. C., Zbozinek, T., \& Vervliet, B. (2014). Maximizing exposure therapy: An inhibitory learning approach. Behaviour Research and Therapy, 58, 10-23. https://doi.org/10.1016/j.brat.2014.04.006

D’Astolfo, L., \& Rief, W. (2017). Learning about expectation violation from prediction error paradigms - A meta-analysis on brain processes following a prediction error. Frontiers in Psychology, 8, Article 1253. https://doi.org/10.3389/fpsyg.2017.01253

Delgadillo, J., Moreea, O., \& Lutz, W. (2016). Different people respond differently to therapy: A demonstration using patient profiling and risk stratification. Behaviour Research and Therapy, 79, 15-22. https://doi.org/10.1016/j.brat.2016.02.003

Dey, S., Joormann, J., Moulds, M. L., \& Newell, B. R. (2018). The relative effects of abstract versus concrete rumination on the experience of post-decisional regret. Behaviour Research and Therapy, 108, 18-28. https://doi.org/10.1016/j.brat.2018.06.007

Enck, P., Bingel, U., Schedlowski, M., \& Rief, W. (2013). The placebo response in medicine: Minimize, maximize or personalize? Nature Reviews: Drug Discovery, 12(3), 191-204. https://doi.org/10.1038/nrd3923

Everaert, J., Bronstein, M. V., Cannon, T. D., \& Joormann, J. (2018). Looking through tinted glasses: Depression and social anxiety are related to both interpretation biases and inflexible negative interpretations. Clinical Psychological Science, 6, 517-528.

Gehrt, T. B., Carstensen, T. B. W., Ørnbøl, E., Fink, P. K., Kasch, H., \& Frostholm, L. (2015). The role of illness perceptions in predicting outcome after acute whiplash trauma: A multicenter 12month follow-up study. The Clinical fournal of Pain, 31(1), 14-20.

https://doi.org/10.1097/AJP.0000000000000085

Glombiewski, J. A., Holzapfel, S., Riecke, J., Vlaeyen, J., de Jong, J., Lemer, G., \& Rief, W. (2018). Exposure and CBT for chronic back pain: An RCT on differential efficacy and optimal length of treatment. fournal of Consulting and Clinical Psychology, 86(6), 533-545. https://doi.org/10.1037/ccp0000298

Gotlib, I. H., \& Joormann, J. (2010). Cognition and depression: Current status and future directions. In S. Nolen-Hoeksema, T. D. Cannon, \& T. Widiger (Eds.), Annual Review of Clinical Psychology (Vol. 6, pp. 285-312). https://doi.org/10.1146/annurev.clinpsy.121208.131305

Greenberg, T., Chase, H. W., Almeida, J. R., Stiffler, R., Zevallos, C. R., Aslam, H. A., . . Phillips, M. L. (2015). Moderation of the relationship between reward expectancy and prediction errorrelated ventral striatal reactivity by anhedonia in unmedicated major depressive disorder: Findings from the EMBARC study. The American fournal of Psychiatry, 172(9), 881-891. https://doi.org/10.1176/appi.ajp.2015.14050594

Heim, C., Newport, D. J., Mletzko, T., Miller, A. H., \& Nemeroff, C. B. (2008). The link between childhood trauma and depression: Insights from HPA axis studies in humans. Psychoneuroendocrinology, 33(6), 693-710. https://doi.org/10.1016/j.psyneuen.2008.03.008

Holm, L. W., Carroll, L. J., Cassidy, J. D., Skillgate, E., \& Ahlbom, A. (2008). Expectations for recovery important in the prognosis of whiplash injuries. PLoS Medicine, 5(5), Article e105. https://doi.org/10.1371/journal.pmed.0050105 
Holmes, E. A., Ghaderi, A., Harmer, C. J., Ramchandani, P. G., Cuijpers, P., Morrison, A. P., . . Craske, M. G. (2018). The Lancet Psychiatry Commission on psychological treatments research in tomorrow's science. The Lancet: Psychiatry, 5(3), 237-286.

https://doi.org/10.1016/S2215-0366(17)30513-8

Horwitz, A. G., Berona, J., Czyz, E. K., Yeguez, C. E., \& King, C. A. (2017). Positive and negative expectations of hopelessness as longitudinal predictors of depression, suicidal ideation, and suicidal behavior in high-risk adolescents. Suicide \& Life-Threatening Behavior, 47(2), 168-176. https://doi.org/10.1111/sltb.12273

Insel, T. R. (2014). The NIMH research domain criteria (RDoC) project: Precision medicine for psychiatry. The American fournal of Psychiatry, 171(4), 395-397. https://doi.org/10.1176/appi.ajp.2014.14020138

Joormann, J., \& Quinn, M. E. (2014). Cognitive processes and emotion regulation in depression. Depression and Anxiety, 31(4), 308-315. https://doi.org/10.1002/da.22264

Keltner, J. R., Furst, A., Fan, C., Redfern, R., Inglis, B., \& Fields, H. L. (2006). Isolating the modulatory of expectation on pain transmission: A functional magnetic resonance imaging study. The Journal of Neuroscience: The Official Fournal of the Society for Neuroscience, 26(16), 4437-4443. https://doi.org/10.1523/JNEUROSCI.4463-05.2006

Kim, D., Yoon, K. L., \& Joormann, J. (2018). Remoteness and valence of autobiographical memory in depression. Cognitive Therapy and Research, 42(3), 230-235.

https://doi.org/10.1007/s10608-017-9881-6

Koyama, T., McHaffie, J. G., Laurienti, P. J., \& Coghill, R. C. (2005). The subjective experience of pain: Where expectations become reality. Proceedings of the National Academy of Sciences of the United States of America, 102(36), 12950-12955. https://doi.org/10.1073/pnas.0408576102

Kube, T., D’Astolfo, L., Glombiewski, J. A., Doering, B. K., \& Rief, W. (2017). Focusing on situationspecific expectations in major depression as basis for behavioural experiments - Development of the Depressive Expectations Scale. Psychology and Psychotherapy: Theory, Research and Practice, 90(3), 336-352. https://doi.org/10.1111/papt.12114

Kube, T., Rief, W., Gollwitzer, M., Gärtner, T., \& Glombiewski, J. A. (2018a). Why dysfunctional expectations in depression persist - Results from two experimental studies investigating cognitive immunization. Psychological Medicine. Advance online publication. https://doi.org/10.1017/S0033291718002106

Kube, T., Rief, W., Gollwitzer, M., \& Glombiewski, J. A. (2018b). Introducing an experimental paradigm to investigate expectation change (EXPEC). Fournal of Behavior Therapy and Experimental Psychiatry, 59, 92-99. https://doi.org/10.1016/j.jbtep.2017.12.002

Kube, T., Siebers, V. H. A., Herzog, P., Glombiewski, J. A., Doering, B. K., \& Rief, W. (2018c). Integrating situation-specific dysfunctional expectations and dispositional optimism into the cognitive model of depression - A path-analytic approach. fournal of Affective Disorders, 229, 199-205. https://doi.org/10.1016/j.jad.2017.12.082

Liknaitzky, P., Smillie, L. D., \& Allen, N. B. (2017). Out-of-the-blue: Depressive symptoms are associated with deficits in processing inferential expectancy-violations using a novel cognitive 
rigidity task. Cognitive Therapy and Research, 41(5), 757-776.

https://doi.org/10.1007/s10608-017-9853-x

Liu, W. H., Roiser, J. P., Wang, L. Z., Zhu, Y. H., Huang, J., Neumann, D. L., . . Chan, R. C. K. (2016). Anhedonia is associated with blunted reward sensitivity in first-degree relatives of patients with major depression. Journal of Affective Disorders, 190, 640-648.

https://doi.org/10.1016/j.jad.2015.10.050

Manes, S., Nodop, S., Altmann, U., Gawlytta, R., Dinger, U., Dymel, W., . . Strauss, B. (2016). Social anxiety as a potential mediator of the association between attachment and depression. fournal of Affective Disorders, 205, 264-268. https://doi.org/10.1016/j.jad.2016.06.060

McCullough, J. P. (2000). Treatment for chronic depression: Cognitive Behavioral Analysis System of Psychotherapy. New York, NY, USA: Guilford Press.

McCullough, J. P., Jr., Lord, B. D., Martin, A. M., Conley, K. A., Schramm, E., \& Klein, D. N. (2011). The significant other history: An interpersonal-emotional history procedure used with the early-onset chronically depressed patient. American fournal of Psychotherapy, 65(3), 225-248. https://doi.org/10.1176/appi.psychotherapy.2011.65.3.225

McEvoy, P. M., Hyett, M. P., Ehring, T., Johnson, S. L., Samtani, S., Anderson, R., \& Moulds, M. L. (2018). Transdiagnostic assessment of repetitive negative thinking and responses to positive affect: Structure and predictive utility for depression, anxiety, and mania symptoms. Fournal of Affective Disorders, 232, 375-384. https://doi.org/10.1016/j.jad.2018.02.072

McLaughlin, K. A., Koenen, K. C., Bromet, E. J., Karam, E. G., Liu, H., Petukhova, M., . . Kessler, R. C. (2017). Childhood adversities and post-traumatic stress disorder: Evidence for stress sensitisation in the World Mental Health Surveys. The British fournal of Psychiatry, 211(5), 280-288. https://doi.org/10.1192/bjp.bp.116.197640

Morris, S. J. (1997). Performance evaluation in subclinical depression: It looks like I did as poorly as I expected to. Fournal of Psychopathology and Behavioral Assessment, 19(1), 63-74. https://doi.org/10.1007/BF02263229

Nelson, J., Klumparendt, A., Doebler, P., \& Ehring, T. (2017). Childhood maltreatment and characteristics of adult depression: Meta-analysis. The British fournal of Psychiatry, 210(2), 96-104. https://doi.org/10.1192/bjp.bp.115.180752

Oliver, J. M., \& Baumgart, E. P. (1985). The Dysfunctional Attitude Scale: Psychometric properties and relation to depression in an unselected adult-population. Cognitive Therapy and Research, 9(2), 161-167. https://doi.org/10.1007/BF01204847

Pizzagalli, D. A. (2014). Depression, stress, and anhedonia: Toward a synthesis and integrated model. In T. D. Cannon \& T. Widiger (Eds.), Annual Review of Clinical Psychology (Vol. 10, pp. 393-423). https://doi.org/10.1146/annurev-clinpsy-050212-185606

Rheker, J., Winkler, A., Doering, B. K., \& Rief, W. (2017). Learning to experience side effects after antidepressant intake - Results from a randomized, controlled, double-blind study. Psychopharmacology, 234(3), 329-338. https://doi.org/10.1007/s00213-016-4466-8 
Rief, W., Bingel, U., Schedlowski, M., \& Enck, P. (2011). Mechanisms involved in placebo and nocebo responses and implications for drug trials. Clinical Pharmacology and Therapeutics, 90(5), 722-726. https://doi.org/10.1038/clpt.2011.204

Rief, W., \& Glombiewski, J. A. (2016). Erwartungsfokussierte psychotherapeutische Interventionen (EFPI) [Expectation-focused psychological intervention (EFPI)]. Verhaltenstherapie, 26(1), 47-54. https://doi.org/10.1159/000442374

Rief, W., \& Glombiewski, J. A. (2017). The role of expectations in mental disorders and their treatment. World Psychiatry: Official fournal of the World Psychiatric Association (WPA), 16(2), 210-211. https://doi.org/10.1002/wps.20427

Rief, W., Glombiewski, J. A., Gollwitzer, M., Schubö, A., Schwarting, R., \& Thorwart, A. (2015). Expectations as core features of mental disorders. Current Opinion in Psychiatry, 28(5), 378-385. https://doi.org/10.1097/YCO.0000000000000184

Rief, W., Shedden-Mora, M., Laferton, J. A. C., Auer, C., Petrie, K. J., Salzmann, S., . . Moosdorf, R. (2017). Preoperative optimization of patient expectations improves long-term outcome in heart surgery patients: Results of the randomised controlled PSY-HEART trial. BMC Medicine, 15(1), Article 4. https://doi.org/10.1186/s12916-016-0767-3

Schedlowski, M., Enck, P., Rief, W., \& Bingel, U. (2015). Neuro-bio-behavioral mechanisms of placebo and nocebo responses: Implications for clinical trials and clinical practice. Pharmacological Reviews, 67(3), 697-730. https://doi.org/10.1124/pr.114.009423

Seth, A. K., Suzuki, K., \& Critchley, H. D. (2012). An interoceptive predictive coding model of conscious presence. Frontiers in Psychology, 2, Article 395.

https://doi.org/10.3389/fpsyg.2011.00395

Sharot, T., Korn, C. W., \& Dolan, R. J. (2011). How unrealistic optimism is maintained in the face of reality. Nature Neuroscience, 14(11), 1475-1479. https://doi.org/10.1038/nn.2949

Sharot, T., Riccardi, A. M., Raio, C. M., \& Phelps, E. A. (2007). Neural mechanisms mediating optimism bias. Nature, 450(7166), 102-105. https://doi.org/10.1038/nature06280

Sumner, J. A., Griffith, J. W., \& Mineka, S. (2010). Overgeneral autobiographical memory as a predictor of the course of depression: A meta-analysis. Behaviour Research and Therapy, 48(7), 614-625. https://doi.org/10.1016/j.brat.2010.03.013

Vögtle, E., Barke, A., \& Köner-Herwig, B. (2013). Nocebohyperalgesia induced by social observational learning. Pain, 154(8), 1427-1433. https://doi.org/10.1016/j.pain.2013.04.041

Wager, T. D., Rilling, J. K., Smith, E. E., Sokolik, A., Casey, K. L., Davidson, R. J., . . Cohen, J. D. (2004). Placebo-induced changes in fMRI in the anticipation and experience of pain. Science, 303(5661), 1162-1167. https://doi.org/10.1126/science.1093065

Wager, T. D., Scott, D. J., \& Zubieta, J.-K.(2007). Placebo effects on human $\mu$-opioid activity during pain. Proceedings of the National Academy of Sciences of the United States of America, 104(26), 11056-11061. https://doi.org/10.1073/pnas.0702413104

Wilson, R. P., Colizzi, M., Bossong, M. G., Allen, P., Kempton, M., \& Bhattacharyya, S. (2018). The neural substrate of reward anticipation in health: A meta-analysis of fMRI findings in the 
monetary incentive delay task. Neuropsychology Review, 28(4), 496-506.

https://doi.org/10.1007/s11065-018-9385-5 